Rece. Sande mibl., S. Paulo

12:99-10:3. 1978

\title{
IDENTIFICAÇÃO POR CONTRAIMUNOELETROFORESE DE ROTAVIRUS EM CASOS DE DIARRÉIA INF'ANTIL *
}

J. A. N. Candeias **

Cornélio P. Rosenburg ***

M. L. Rácz **

RSPUB9/:398

CANDEIAS, J. A. N. et al. Identificação por contraimunoeletroforese de rotavirus em casos de diarréia infantil. Rev. Saúde públ., S. Pallo, 12:99-103, 1978.

RESUMo: Os resultados obtidos na identificação de rotavirus, usando a técnica da contraimunoeletroforese, com 162 ainostras de feses de crianças com quadros diarréicos agudos, mostram umo distribuição percentual de positividade de $72,7 \%, 77,7 \%$ e 66,6\% em diferentes grupos etários de 6 a 8 meses até um ano de idade.

UNITERMOS: Rotavirus (Orbivirus). Imunoeletroforese. Diarréia infantil.

\section{N T R O D U C A O}

A gastroenterite infantil não bacteriana, gastroenterite viral infantil, ou gastroenterite viral B é uma entidade etiologicamente bem definida, em que particulas virais de 65 a $75 \mathrm{~nm}$ têm sido, encontradas na maior parte dos pacientes por microscopia eletrônica, quando examinados os extratos fecais por esta técnica $5-8,12.13 .16,2,2,27,31,33$.

Estas partículas são hoje conhecidas pela designação de rotavírus ${ }^{1+}$. Estudos feitos por Kapikian e col. 22, utilizando a reação de fixação do complemento, demonstraram ser os rotavírus agentes relativamente ubiquitários, pelo menos, nas áreas em que aqueles autores fizeram os levantamentos sorologicos. Os rotavirus podem infectar, além do homem, outros animais, como bovinos 25.37 , equinos 15.39 , ovinos 32 , porcinos is, murinos 1,28 e leporinos 9, já sendo possivel identificar de que espécie foram isolados utilizando-se provas de neutralização ${ }^{34}$. Utilizando como antigeno, uma cêpa bovina de rotavírus (N. C. D. V.), Kapikian e col.²1 demonstraram, sorologicamente, a infecção de crianças por rotavírus humanos. Esta relação antigênica entre rotavírus humanos e bovinos tem aplicações práticas de grande valia. considerando-se a viabilidade de replicação dos rotavírus bovinos em culturas celulares. Os métodos de diagnóstico utilizados para a identifi(ação de rotavirus vão descle a visualização)

* Pesquisa financiada pelo Departamento de Assistencia à Infância e Maternidade da Secretaria de Educação da Prefeitura Municipal de São Paulo.

* Do Departamento de Microbiologia e Imunologia do Instituto de Ciências Biomédicas da USP - "Setor Saúde Pública" - Ar. Dr. Arnaldo, 715 - São Paulo, SP - Brasil.

** Do Departamento de Saúde Materno-Infantil da Faculdade de Saúde Pública da USP Ar. Dr. Arnaldo, 715 - São Paulo, SP - Brasil. 
CANDEIAS. J. A. N. et al. Identificação por contraimunoeletroforese de rotarirus em casos de diarréla infantil. Rev. Saude publ., S. Paulo. 12:99-103, 1978.

das particulas virais por microscopia eletrônica i.1ts e imunoeletronicroscopia": até à identificação de antígenos por imunofluorescência $:$, e contraimunoeletroforese ${ }^{3 . i^{-}}$, a pescluisa de anticorpos pode ser feital por fixação do complemento $: 1$, neutralização ' e imunofluorescência.: $: 9$

No presente trabalho apresentam-se os resultados obtidos com a utilização da técnica da contraimunoeletroforese no diagnóstico da gastroenterite viral $B$.

\section{MATERIAL E MÉTODOS}

\section{Amostras de fezes}

Foram estudadas 164 amostras de fezes obtidas de crianças com quadros diarréicos agudos. A colheita foi feita com zaragatoa estéril conservada em meio de transporte especial: , os extratos para exame foram preparados segundo técnica descrita por Bishop e col.o e conservados a-200 $\mathrm{C}$, até ulterior utilizaçāo.

\section{Soro onti-rotavirus}

A cêpa "Comptun-England" de virus da diarréia de vitelos, cedida pelo Dr. T. H. Flewwtt, foi cultivada en culturas de rim de hovino te purificada pela técnica de Bishop e col.5, sem ultracentrifugação en gradiente de sacarose. O material obtido, depois de misturado con adjuvante completo de Freund, foj utilizado para a imunização de cobaias, por via subeutânia, en três inoculações de $0,5 \mathrm{ml}$ com 15 dias de intervalo; 0 soro obtido na sangria de prova. feita no 45" chia, permitiu estabelecer a identidade dos anticorpos frente a extratos fecais humanos com provas de difusão en agar positivas para um soro padrão antirotavirus, para soros humanos convalescentes, oriundos de casos de gastroenterite infantil e para soros de bovinos adultos con anticorpos precipitantes para a cêpa "Compton-England".

\section{Contraimunocletroforese}

A contraimunoletroforese foi feita em làminas de vidro $(5,0 \times 7,5 \mathrm{~cm})$ cobertas com $6 \mathrm{ml}$ de agar a $0,9 \%$, preparado em tampã de veronal acetato pH s.6 e força iônica igual a $0,1 \mu$. Em cacła lâmina foram feitas depressóes con diametro de 3 mm. separadas entre si de uma distancia de 3 mm. de modo a obter-se um padrão de duas fileiras duplas de 6 depressōes; em cacla lâmina podiam, deste modo, testar-se 12 extratos de fezes. As amostras de soro especifico. depois de inativadas a $56^{\circ} \mathrm{C}$, durante 5 min., foram colocadas nas depressies dispostas do lado do ânodo, enquanto os extratos de fezes, não diluidos, foram colocados do lado do cátodo. A contraimunoeletroforese foi feita con una corrente constante de $1211 \mathrm{~A}$ por lâmina, durante um periodo de $60 \mathrm{~min}$. à temperatura ambiente (cerca de $24^{\circ} \mathrm{C}$ ); passado este tempo, as linhas de precipitado eram, de um modo geral, perfeitamente risiveis, contra fundo escuro e sob iluminaçāı tangencial, não tench sido necessário fazer sla coloração.

\section{RESULTADOS}

Na Tabela apresentan-se us resultados obtidos con as 162 amostras cle fezes, segundo a jdade das crianças estudadas. Pode observar-se un acentuado aumento das percentagens de positividade a partir da classe de 6 a 8 meses, elevaçāo esta que se mantém nas classes subseqüentes.

\section{DISCUSSÃO}

A visualização de rotavírus por microscopia eletrônica é un método de elevada eficiència e rapidez, mas exige obviamente. uma aparelhagem de custo elevado. além do que apresenta limitaçós de orden operacional. quando o numero de exames diarios é superior a duas dezenas, situaçãu de ocorrencia freqüuente $\overline{-16.19 .2+.2 f_{1} 2^{-}}$

\footnotetext{
* "Securline" - Precision Dynamics Corporation 30.3 Thornton Ar. Burbank. Calif 91504
} 
CANDEIAS. J. A. N. et al. Identificaçăo por contraimunoeletroforese de rotavirus em rasos de diarritia tufantil. Rel. Sande publ., S. Paulo, 12:99-1013, 1978.

T A B E L A

Rcsultado da contraimunoeletroforese na identificação de rotavírus em extratos de fezes de crianças com quadros diarréicos agudos.

\begin{tabular}{|c|c|c|c|}
\hline \multirow{2}{*}{$\begin{array}{c}\text { Idade } \\
\text { (meses) }\end{array}$} & \multirow{2}{*}{$\begin{array}{l}\text { N Casos } \\
\text { Estudados }\end{array}$} & \multicolumn{2}{|c|}{ Casos Positivos } \\
\hline & & Ne & $\%$ \\
\hline$\leqslant 1$ & 52 & 5 & 9,6 \\
\hline $21-4$ & 48 & 3 & 6,2 \\
\hline $4 \mid-6$ & 30 & 3 & 10,0 \\
\hline $61-8$ & 11 & 8 & 72,7 \\
\hline $8-10$ & 9 & 7 & 77,7 \\
\hline $10|-| 12$ & 12 & 8 & 66,6 \\
\hline Total & 162 & 34 & 20,9 \\
\hline
\end{tabular}

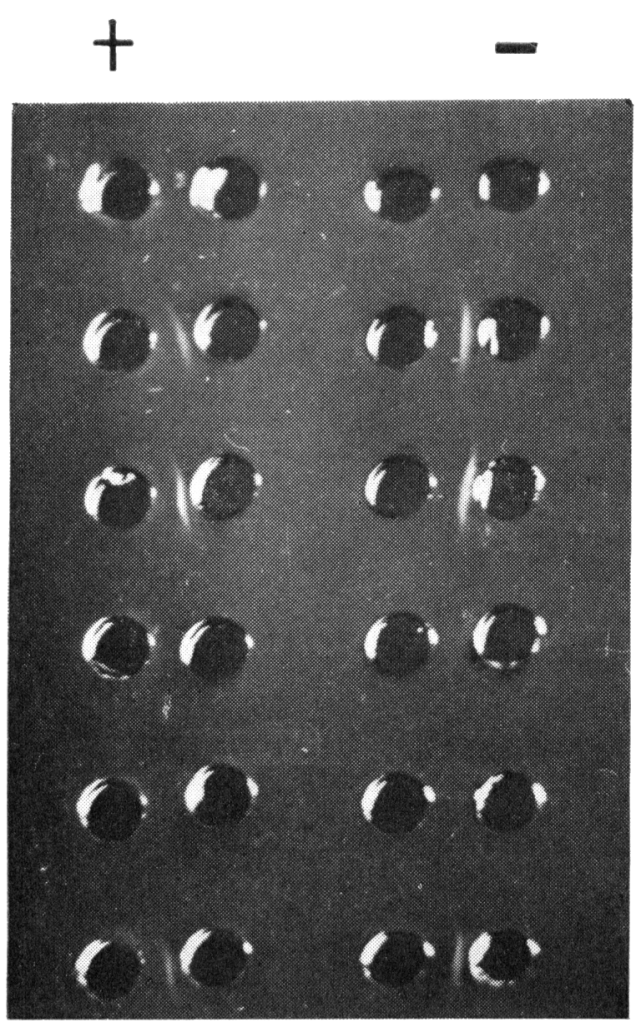

COLUNA COLUNA

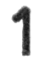

Figura - Identificação de rotavirus em 6 ex. tratos fecais utilizando soro anti-rotavirus obtido por imunizaçăo de cobaias (coluna 1) e uma mistura de soros de bovinos adultos (coluna 2)
A possibilidade de identificação de rotavirus através da reação de fixação do conıplemento rão deve ser considerada como promissora dado que os extratos fecais são, frecüentemente, anticomplementares $\%$. A contraimunoeletroforese apresenta-se como um método qualitativo de grande simplicidade e rapidez, capaz de detectar pequenas quantidades de antígenos com mobilidade eletroforética relativamente rápida. Este método tem sido utilizado com bons resultados para a identificação de diversos antígenos virais $3.17 .18,20$. No caso dos rotaviru: a contraimunoeletroforese mostrou ser um método rápido e econômico, dando resultados comparáveis aos da microscopia eletrônica e pociendo identificar particulas virais incompletas $2(i .35$. Nossos resultados confirnam a utilidade do referido método e, quando analisados em termos das percentagens de positividade obtidas, conforme a Tabela, assemelham-se aos obtidos por outros autores $10.11,3.5$.

A Figura ilustra a identificação contraimunoeletroforética de rotavírus em 6 extratos fecais, testados em duplicata, contra o soro anti-rotavírus preparado em cobaia e contra uma mistura de soros de bovinos adultos, que en testes prévios de difusão enı gel de agar, frente à cêpa "ComptonEngland", tinham dado uma precipitação especifica. A interpretação dos resultados é inequívoca e em nenhum dos testes feitos, quando se usou esta mistura, se obtiveram reações não específicas. Estes resultados 
CANDEIAS, I. A. N. et al. Identificaçän por contraimuneletrotorese de rotavirus em casos de diarréia infantil. Rev. Saúde pübl., S. Paulo, 12:99-103, 1978.

sugerem, assim, a possibilidade de se usar, como soro especifico identificador do antigeno do grupo rotavirus, uma mistura de soros de bovinos adultos, onde é comum o encontro de anticorpos que reagem com aquele antigeno. Em relação à técnica de imunofluorescência, Flewett sugere que se use aquela mistura de soros de bovinos adultos, desde que respeitadas determinadas normas: Woode e col.39 demonstraram, pelas provas de difusão em gel de agar, a presença de um antigeno de grupo comum aos rotavírus humanos e bovinos. Rodger e col. 30 consideram que as diferenças existentes nas proteinas da camada externa da cápside de rotavírus humanos e rotavirus buvinos devem ser mínimas. Por outro lado, tanto um como outro grupo de virus não reagem com soros anti-reovirus dos tipos 1, 2 e 3, nem com os soros anti-orbivirus $1 .$. . Resta a consideração dos coronavírus humanos como capazes de ocasionarem quadros de gastroenterite, tal como ocorre com porcinos e bovinos, onde os coronavírus são importante causa de enterite. Esta consideração é meramente especulativa, além de que os coronavirus de bovinos não estão sorologicamente relacionados com os coronavirus humanos:i*

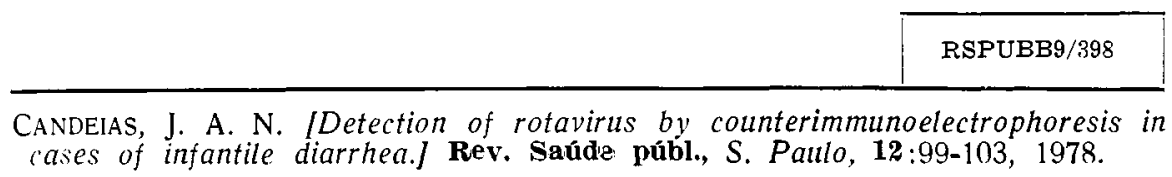

ABSTRACT: The faecal samples of 162 children with acute diarrhea were tested by counterimmunoelectrophoresis in order to detect rotaviruses. In $72.7 \%$, $77.7 \%$ and $66.6 \%$ of samples from children of different age groups, varying from 6 to 8 months to 1 year or older, a positive result was found.

UNITERMS: Rotavirus. (Orbivirus) Immunoelectrophoresis. Diarrhea, infantile.

\section{REFERENCIAS BIBLIOGRAFICAS}

1. ADAMS, W. R. \& KRAFT, L. M. Epizootic diarrhea of infant mice: identification of the etiologic agent. Science, 141: $359-60,1963$.

2. BANATVALA, J. E. et al. In vitro detection of human rotaviruses. Lancet, 2:821, 1975.

3. BELIN, B. S. \& PIROJBOOT, N. A rapid method for demonstration of precipitating antibody against influenza virus by counterimmunoelectrophoresis. J. infect. Dis., $126: 345-7,1972$.

4. BIRCH, C. J, et al. A study of the prevalence of rotavirus infection in children with gastroenteritis admitted to an infectious diseases hospital. $J$. med. Virol., 1:69-77, 1977.

\footnotetext{
* Flewett, T. H. Informaça pessoal
}

5. BISHOP, R. F. et al. Detection of a new virus by electron microscopy of faecal extracts form children with acute gastroenteritis. Lancet, 1:149-51, 1974.

6. BISHOP, R. $\boldsymbol{F}$. et al. Evidence for viral gastroenteritis. New Engl. J. Med. $289: 1096-7,1973$.

7. BISHOP, R. F. et al. Virus particles in epithelial cells of duodenal mucosa from children with acute nonbacterial gastroenteritis. Lancet, $2: 1281-3,197 \%$.

8. BORTOLUSSI, R. et al, Studies on the etiology of acute infantile diarrhea. Pediat. Res. 8:379, 1974

9. BRYDEN, A. S, et al, A rabbit rotavírus. Vet. Rec., 99:323, 1976.

10. BRYDEN, A. S. et al. Rotavirus enteritis in the West Midlands during, 1974. lancet, $1: 241-3,1975$. 


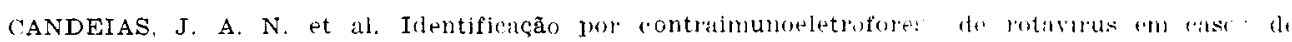
diarréia infantil. Rer. Saude públ., S. Paulo, 12:99-103, 1978.

11. CARR. M. E. et al. The clinical features of infantile gastroenteritis due to rotavirus. Scand. J. infert. Dis., 8: 241-3, 1976.

12. CRUICKSHANK, $\mathbf{J}$. et al. Viruses in gastroenteritis. Lancet, $1: 1353,1974$.

13. DAVIDSON, G. P. et al, Importance of a new virus in acute sporadic enteritis in children. Lancet, 1:242-5, 1975

14. FLEWETT, T. H. et al. Relation between viruses from acute gastroenteritis of children an newborn ralves. Lancet, 2:61-3, 1974 .

15. FLEWETT, $T$, $H$, et al, Virus diarboea in foals and other animals. Vet. Rec. $96: 477,1975$.

16. FLEWETT, $T$. $H$, et al. Virus particles in gastroenteritis. Lancet, 2:1497, 1973.

17. FORTUNATO, J, et al. Rapid detection of antibodies to cytomegalovirus by counterimmunoelectrophoresis. $J$. infer. Dis., 135:432-7, 1977.

18. GOCKE. D. J. \& HOWE, C. Rapid detection of Australia antigen by counterimmunoelectrophoresis. $J$, Immunol., 104 : $1031-2, \quad 1970$

19. GOMEZ-BARRETO. J. et al. Acute enteritis associated with reovirus - like agents. J. Amer, med. Ass., 235:1857-60, 1976.

20. HIERHOLZER, J. C. \& BARME, M. Counterimmunoelectrophoresis with adenovirus type-specific antihemaglutin sera as a rapid diagnostic method. $J$. $\mathrm{Im}$ munol., 112:987-95, 1974.

21. KAPIKIAN, A. Z et al. New complement - fixation test for the human reovirus-like agent of infantile gastroenteritis, Lancet, 1:1056-60, 1975.

22. KAPIKIAN, A. $Z$. et al. Reoviruslike agent in stools: Association with infantile diarrhea and development of serologic tests. Science, 185:1049-53. 1974

2:3. KAPIKIAN, A. $Z$, et al. Visualization by immune electron microscopy of a. 27$\mathrm{nm}$ particle associated with acute infectious nonbacterial gastroenteritis. J. Virol., $10: 1075-81,1972$.

24. MADELEY, C. R, et al. Stool viruses in babies in Glasgow. J. Hyg., Cambridge, 78:261-73, 1977.

25. MEBUS, C. A. et al. Calf diarrhoea (scours) reproduced with a virus from a fjeld outbreak, Nebr. Agric. Exp. Stat. Res. Bull. (233):1-16, 1969.

26. MIDDLETON, P. J. et al. Counter-immunoelectroosmophoresis for the detection of infantile gastroenteritis virus (orbigroup) antigen and antibody. $J$. clin. Pathol., 29:191-7. 1976.

27. MIDDLETON, $P$. J. et al. Orbivirus acute gastroenterites of infancy. Lancet, 1 $1241-4,1974$

28. MUCH, D. H. \& ZAJAC, I. Purification and characterization of epizootic diarrhoea of infant mice virus. Infert. Immun., 6:1019-24. 1972.

29. ORSTAVIK, I. \& HAUG, K. W. Virusspecific IgM antibodies in acute gastroenteritis due to a reovirus-like agent (Rotavirus). Scand. $J$. infert. Dis., 8:2:37-40, 1976.

30. RODGER, S. M. et al. Biochemical and biophysical characteristics of diarrhoea virus of human and calf origin $J$ Virol., 16:1229-35, 1975.

31. ROTAVIRUS of man and animals Lanc $t$, $1: 257-9.1975$

32. SNODGRASS, D. R. et a1. A rotavirus in lambs with diarrhoea. Res. Vet. Sct. $20: 113-4,1976$.

32. TANG, G. S. et al. Virus in faecal axtracts from children with gastroenteritis, Lancet, 1:1109. 1974.

34. THOULESS, M. E, et al. Sorologicial relationship between rotaviruses from different species as studied by complenent fixation and neutralization. Arch. Virol., 53:287-94, 1977.

35. TUFVESSON, B. \& JOHNSSON, T. Immunoeletroosmophoresis for detection of reo-like virus: methodology and comparison with electron microscopy. Acta path. microbiol. scand. Sect. $B, 84$ : 225-8, 1976.

36. TYRRELL, D. A. J. et al. Coronaviridap. Intervirology, 5:76-82, 1975.

37. WOODE, G. N. et al, The isolation of : reovirus-like arent associated with diarrhoea in colostrum-deprived calres in Great Britain. Res. Vet. Sci,, 16 $102-5$, 1974 .

38. WOODE, G. $N$. et al. The isolation of reovirus-like agents (rotaviruses) from arute gastroenteritis of piglets. $f$ med. Microbiol, 9:203-9, 1976.

39. WOODE, G. N. et al. Morphological an 1 antigenic relationships between virus ss (Rotaviruses) from acute gastroenterltis of children, calves, piglets, mice and foals. Infert. Immun. 14:804-10, 1976 .

Recebias para publicaçă 6 'm ll/08; Aprovude, para publicação em ir/08; 